\title{
DRAMATURGIA ESPECTACULAR. ENFOQUE TEÓRICO DE TADEUSZ KANTOR
}

\author{
SCENIC DRAMATURGY. TADEUSZ KANTOR'S \\ THEORETICAL APPROACH
}

\author{
Julia NAWROT \\ Universidad de Granada \\ jnawrot@ugr.es
}

\begin{abstract}
Resumen: Para Tadeusz Kantor cada espectáculo fue una especie de manifiesto artístico: desde el teatro autónomo, pasando por teatro informel, teatro cero y teatro imposible, al más conocido Teatro de la Muerte. El presente artículo indaga en el proceso de construcción de las obras de Kantor en el marco de su pensamiento crítico-teórico original.
\end{abstract}

Palabras clave: Tadeusz Kantor. Teatro. Teoría. Dramaturgia.

Abstract: Tadeusz Kantor saw each and every spectacle as an artistic manifesto: starting with the Autonomous Theatre, through the Informel Theatre, the Zero Theater and the Impossible Theater, and ending with his well-known idea of the Theatre of Death. This paper explores Kantor's creation process in the frame of his groundbreaking critical and theoretical thought.

Key Words: Tadeusz Kantor. Theatre. Theory. Dramaturgy. 


\section{TADEUSZ KANTOR Y EL TEATRO CRICOT 2}

"La evolución del arte no depende únicamente de los aspectos formales sino que es, sobre todo, un movimiento permanente de pensamientos e ideas" (Kantor, 2010: 93). Tadeusz Kantor siempre subrayaba la importancia del comentario -en forma de ensayo, notas, apuntes o manifiestos explícitos- de toda su actividad artística: fuese pintura, instalaciones, happenings o teatro. En el campo del arte escénico la reflexión teórica estaba muy presente, ya que el artista investigó incansablemente y, como dijimos en otra ocasión (Nawrot, 2015), cada espectáculo fue una especie de manifiesto artístico. Kantor insistía en que el teatro debería "descubrir su propia materia, su energía y sus medios de expresión" (2005a: 156) ${ }^{1}$, y no limitarse a transmitir la literatura. Para él, el teatro no era un medio de reproducción de textos literarios, sino un espacio libre e independiente, donde el texto dramático previo o texto en general era sólo uno de los elementos que confluían en la totalidad del espectáculo. Asimismo, era importante que el teatro se nutriera del Arte (con mayúsculas), de sus ideas $\mathrm{y}$ tendencias.

Por ese motivo en la compañía de teatro Cricot 2, que Tadeusz Kantor fundó en el año 1955 junto con Maria Jarema y Kazimierz Mikulski, tuvieron cabida artistas de diversa proveniencia: actores, pintores, poetas o músicos. Todos ellos tenían inquietudes que se salían de sus respectivos campos de interés, y proponían nuevas ideas que traspasaban los tradicionales límites del Arte. En palabras del propio Kantor (2005a: 156): entre todos "estaban intentando crear una nueva situación en el Arte", y el teatro resultó ser el espacio propicio donde estas ideas pudieron entrar en interacción directa.

La manera de trabajar del Teatro Cricot 2 puede resultar curiosa, dado que desde su inicio se rechazaron los conceptos de estreno y repertorio, siendo sustituidos por el concepto de etapa. De esa forma Kantor se desvinculaba del teatro convencional, burgués, que a sus ojos se había convertido en una fábrica de espectáculos producidos en cadena con el objetivo de llenar la temporada.

1. Las traducciones de todas las citas provenientes de las referencias bibliográficas en polaco son nuestras. 
El Teatro Cricot 2 constantemente socavaba esos principios universales de una organización aparente, que en realidad no tiene en cuenta las leyes del proceso creativo y de la imaginación. La estructura del teatro Cricot 2 asume que el trabajo en el teatro tiene que ser creativo. Suprime la rigurosa división artificial entre el trabajo y el resultado, entre los ensayos y el espectáculo.

Esta división tan arraigada que es muy dificil imaginarse otra, y por ello se cree que es la única y natural, es en realidad contraria al arte y la creación.

Independientemente de la especificidad del teatro, la creación siempre y en cada campo consiste sobre todo en el descubrimiento de "lo nuevo" y de "lo imposible", en una revolución.

Existe totalmente en tiempo y en espacio.

Esta división espacio-temporal fija y artificial:

trabajo - resultado, ensayos - espectáculo, sala de ensayos - escenario elimina la creación de manera inexorable (Kantor, 2005a: 160).

Kantor encontró la verdadera libertad del proceso creativo en el hecho de disponer de todo el tiempo necesario para cada uno de los proyectos teatrales que quería desarrollar. Más de un cuarto de siglo después de su muerte en diciembre de 1990 -y la posterior disolución de Cricot 2- contamos con una distancia suficiente que nos permite tener una visión del conjunto de su obra dividida en varias etapas. Etapas que fueron condicionadas por el continuo "movimiento de ideas" (Kantor, 2005a: 126), y que a su vez se dividían en un período de creación y uno de explotación del espectáculo resultante.

Ahora bien, el período de creación consistía en la búsqueda de nuevas formas de expresión y de nuevos contenidos. Se partía de elementos bastante vagos, incluso de intuiciones o presentimientos, o simplemente de la negación de lo ya conocido. A través de un largo tiempo de profunda investigación interdisciplinar, y de discusiones teóricas, se llegaba a to- 
mar conciencia de los nuevos significados, "de conocer y aprender nuevas leyes y normas de actuación" (Kantor, 2005a: 157). Este lento trabajo de preparación siempre se hacía de forma independiente de cualquier texto dramático: Kantor defendía la necesidad de crear un ámbito escénico lo suficientemente fuerte como para que el encuentro con una obra dramática -al fin y al cabo, un sistema extraño- no causara daños en el sistema construido, sino que pudiera ser incorporado en él. Este período de trabajo duraba más o menos un año, y después llegaba el momento del estreno y de explotación del espectáculo.

Para el Teatro Cricot 2 este espacio de tiempo durante el cual mostraban ante el público el fruto de sus búsquedas no era menos importante que la investigación teatral en sí. En ningún caso se producía una ruptura o cesura con el proceso anterior, puesto que en realidad no se ponía en escena un producto finalizado, en el sentido de acabado y rígido, sino que se trataba más bien de una evolución continua. En el espectáculo presentado a menudo se introducían cambios, como consecuencia de dos fenómenos significativos acaecidos durante el período de explotación. Por un lado, se producía una lenta impregnación de la obra por la sensibilidad del público, lo que llevaba a modificar ciertos elementos con el objetivo de conseguir una mejor sinergia con el espectador. Por otro, sin embargo, la fuerza de acción se debilitaba paulatinamente a causa del agotamiento de los medios de expresión utilizados. Los elementos que, en su momento, habían surgido como novedosos y reveladores, se volvían ordinarios, lo que a su vez llevaba a la necesidad de investigar en nuevos terrenos artísticos. Este período de desarrollo y posterior declive duraba en general entre dos y cuatro años, al cabo de los cuales se producía una nueva revolución y empezaba una nueva etapa.

\subsection{Teatro autónomo}

En mayo de 1956 se presenta al público cracoviano el primer montaje del Teatro Cricot 2, La sepia: una obra basada en el texto dramático del mismo título de Stanisław Ignacy Witkiewicz. En sus apuntes, donde comenta el proceso de construcción de este espectáculo, Kantor (2005a: 140-142) describe de forma muy detallada el complejo trabajo de hermenéutica de la obra que había realizado. Estamos ante un texto de contenido absurdo y antinaturalista, en cuyas didascalias, sin embargo, se describe de 
forma muy minuciosa y realista los rasgos de los personajes (su apariencia externa y su vestuario) y del espacio escénico. Esta paradoja inicial lleva a Kantor a pensar que se trata de un juego carnavalesco de disfrazarse con el objetivo de confundir al espectador, que Witkiewicz proponía al estilo de la Commedia dell'Arte. Un procedimiento perteneciente a una vanguardia histórica que él se niega a adoptar en su espectáculo, considerándolo una idea anticuada y sin la fuerza suficiente para hacer de soporte al potente texto dramático. Kantor argumenta que la realidad literaria de la obra es muy distinta de su realidad física en el escenario, lo que requiere otros medios de expresión.

De ahí que en la construcción de La sepia se utilizaran motivos, temas o algunas de las escenas del drama de Witkiewicz, cuestionando al mismo tiempo el significado y la posición de los personajes frente a los elementos materiales y visuales. La no-reproducción y la no-interpretación del texto literario trasladaban la obra dramática a otra dimensión. En este primer espectáculo de Cricot 2 se rompía con la idea del teatro tradicional contraponiéndole la del teatro autónomo. En su primera etapa de trabajo, la compañía abogaba por el carácter independiente del teatro, no subyugado a la literatura. No se trataba de una representación o una puesta en escena de un texto dramático, sino de una nueva creación compuesta de varios elementos. Como explicó el mismo Kantor:

Esos elementos son:

el entorno (environnement),

los objetos,

el actor

y sus propiedades únicas:

- la dinámica,

- la capacidades de la alta capacidad de cambios psíquicos y emocionales,

- la propiedad de reflejo, de reacción en los matices infinitamente pequeños,

las acciones,

las situaciones,

incidencias, acontecimientos.

Estos elementos podrían influir en el cambio del texto, la fábula o la acción - si tuvieran la función de explicar, 
comentar e ilustrar.

Como no la tienen - porque esa es mi premisa - no son capaces de cambiar nada.

Tan sólo crean un sistema de relaciones

(Kantor, 2000: 152).

En el teatro autónomo, el espectáculo es un sistema de signos interconectados, donde cada uno de los elementos posee su propia autonomía en un escenario despojado de todo tipo de ilusión. Lo que cuenta es la realidad del espectáculo, que no es la realidad objetiva o absoluta, sino la realidad de la puesta en escena. En esta primera etapa del Teatro Cricot 2 se utilizaron ya elementos que serían característicos en toda la obra teatral de Tadeusz Kantor: en La sepia los actores se mueven en el escenario como si fueran maniquíes, en cambio en el Circo, la segunda producción perteneciente al teatro autónomo, aparece la técnica de emballage que consiste en envolver con telas a los actores u objetos, quitándoles la forma y la utilidad propia de su naturaleza.

El caso del Circo, presentado a principios del año 1957, es curioso, ya que se trata de un drama escrito por el pintor Kazimierz Mikulski, uno de los cofundadores de Cricot 2. Es la única ocasión en que Kantor utiliza una obra que no es de Witkiewicz, cuyos textos se convertirían en su principal referencia, lo que explicó en una entrevista con Zbigniew Taranienko (2015: 39) realizada en 1973:

Z.T. ¿Por qué utiliza Usted tan a menudo los textos de Witkiewicz?

T.K. Sobre todo, toda la obra de Witkacy me resulta cercana. Y una cosa más: nosotros no hacemos teatro de repertorio. Es una especie de programa. Antes tenía varias ideas... [...] Pero en algún sentido represento a Witkacy con un objetivo: escogiendo a un solo autor destruyo de alguna forma la idea del teatro de repertorio. Si en este teatro tenemos a un solo autor, quiere decir que este teatro no es una herramienta de divulgación de la literatura en el amplio abanico de posibilidades...

2. Witkacy es el sobrenombre de Stanisław Ignacy Witkiewicz. 
Z.T. Sus obras son además buena materia prima para distintas formas teatrales...

T.K. Hasta el momento - sí. Pero no sé qué ocurrirá más tarde. De todas formas lo estoy haciendo deliberadamente. Hemos creado un teatro anti-repertorio, también subrayando que el teatro es una actividad autónoma y no tiene nada que ver con la literatura. Sólo con uno de sus elementos o con una persona. Existe un motivo.

\subsection{Teatro informel}

El inicio de la década de los sesenta coincide, para Cricot 2, con la etapa del teatro informel, cuyo nombre en francés significa "sin forma", desestructurado, desarticulado. La investigación y teoría teatrales de Tadeusz Kantor estaban precedidas por una búsqueda profunda por medio de la pintura ${ }^{3}$. Allí el artista descubre el estado elemental de la realidad: la materia, su fuerza, sus cualidades de continuidad, fugacidad o densidad. Y en el campo teatral busca abarcar y captar la materia que "no se rige por las leyes de construcción, es cambiante y fluida, inacabada; se contrapone a la forma, que es limitada y completa, que no se somete a cambios, es acabada" (Kantor, 2010: 40).

Kantor oponía el art informel (en español: informalismo) al surrealismo:

[...] Si en el surrealismo la imaginación era ese factor que creaba la realidad alucinatoria, y el acto de pintar, simplificando, era tan sólo la reproducción, en este arte la imaginación entra en el medio del proceso de creación, está en alerta permanente, ansiosa, respondiendo en seguida a lo que viene de fuera. La realidad del cuadro no está lista. Está en crecimiento. No se puede prever el epílogo. [...] Es la confrontación de la imaginación humana con la realidad del mundo (Kantor, 2000: 180).

3. Kantor era un artista completo, director de teatro, escenógrafo y pintor, y en su obra todas las disciplinas estaban interconectadas, de ahí que las búsquedas realizadas en uno de los ámbitos artísticos influían en los demás campos. 
Según el director polaco, la obra de arte nunca está cerrada, se sale de los límites previstos, se expande en todas las direcciones, jugando con lo imprevisto e interviniendo en la realidad y en la vida. Y fue en el ámbito teatral donde encontró el gran abanico de posibilidades de la exploración de la materia. "El TEATRO Cricot 2, en los años sesenta, creó la primera manifestación plena del teatro informel, con el mismo grado de radicalismo que en la pintura" (Kantor, 2005a: 182). En esta etapa se utilizó de nuevo la obra dramática de Witkiewicz y la presentación de La casa de campo ante el público tuvo lugar por primera vez en enero de 1961.

La llegada al descubrimiento de los conceptos o definiciones del arte informal en el teatro (Kantor, 2010: 40-44): la materia, sus diferentes tipos y formas de tratarla, la espontaneidad en las acciones, la actividad, los estados emocionales y los diversos comportamientos, etc., fue un proceso lento. Había que conquistar un terreno muy complicado y, hasta el momento, completamente desconocido para el teatro. Una especie de punto de partida para la construcción del espectáculo, lo que Kantor llamaba l'objet trouvé, fue un objeto, en concreto un armario, que "se convirtió en el único espacio escénico, es decir, en el mundo entero" (2005a: 192). La acción de La casa de campo se desarrollaba alrededor, dentro y encima de este objeto, traspasando los límites del sentimiento del ridículo, liberándose de las convenciones sociales y artísticas. Se evocaba el lado quizás más vergonzoso del teatro: el circo como un espacio despojado de prestigio y dignidad. Los personajes se mostraban ineficaces, dominados por la materia, al mismo tiempo daban asco y despertaban compasión.

A través del TEATRO INFORMEL, realizo de forma práctica mi idea de la REALIDAD

DEL MÁS ÍNFIMO RANGO, utilizo el método de la DESTRUCCIÓN,

el método del AZAR (en su plenitud),

opero con mi definición del OBJETO POBRE

y el LUGAR POBRE (Kantor, 2005a: 222).

Todas éstas son unas constantes del arte kantoriano que iban tomando forma a lo largo de todo su amplio período de creación y evolución del Teatro Cricot 2. 


\subsection{Teatro cero}

En 1963, tan sólo dos años después del estreno de La casa de campo, Kantor dirige El loco y la monja. Este espectáculo materializa las ideas de una nueva etapa llamada teatro cero, recogidas también en un manifiesto titulado Teatro autónomo, con el subtítulo de [Manifiesto del teatro cero]. Como vemos, los conceptos básicos del arte kantoriano permanecen y la evolución de la teoría teatral es un proceso fluido. El director polaco utiliza su experiencia para construir cosas nuevas sobre los mismos fundamentos a los que es fiel, i.e. aboga por la realidad independiente del hecho teatral, y habiendo descubierto en el teatro informel la materia pura, decide llevar los valores de significado de los elementos constituyentes del teatro hacia lo más bajo, en un movimiento de descenso. "El proceso de creación se convierte en la realización de lo imposible. El teatro que llamo 'cero' -dice Kantor- no parte de 'cero'. Su esencia es el proceso mismo hacia el vacío y hacia las "proximidades de cero"' (2010: 66).

Este movimiento hacia abajo tiene como objetivo reavivar el proceso artístico, que con el tiempo se ha convertido en una convención, una repetición fácil de procedimientos reconocidos que gozan de cierto prestigio. Se trata de recuperar la frescura del acto creativo. El artista (Kantor, 2005a: 228-229) contrapone el arte ya automatizado a lo que, según él, es su esencia: el estado incierto, volátil, mudable como la vida misma. Ante una obra de esas características cambia también la percepción del espectador, que pasa de ser analítica y simplemente contemplativa, a una especie de coexistencia fluida y casi activa entre el público y los actores, todos ellos en el campo de la realidad del espectáculo. "Reducir a cero / en la práctica vital / significa negar y destruir” (Kantor, 2005a: 242). “iÉse es el proceso de DESINTEGRACIÓN DE LA ILUSIÓN y la única oportunidad de reencontrarse con la REALIDAD!" (Kantor, 2010: 66).

En el [Manifiesto del teatro cero] se retoman los postulados del teatro autónomo: del espectáculo que no es una explicación, ni una interpretación, ni tampoco una equivalencia escénica de la obra dramática. La finalidad última es romper con la cáscara del texto en una atmósfera de escándalo, que provoca una reacción fuerte del espectador. En El loco y la monja no se representa, sino que se comenta y se contesta el drama de Witkiewicz. Los papeles no están adscritos a los actores, que algunas veces los abandonan para retomarlos en otro momento de la acción escénica. 
En palabras de Kantor, el espectáculo es "un molino que muele el texto" (2005a: 240). Y que muele también a los mismos actores.

El escenario de dimensiones muy reducidas (una especie de tarima de madera) está en su mayor parte ocupado por una máquina compuesta de sillas plegables, amontonadas y unidas por un sistema de cuerdas y ganchos. Una máquina que tiene vida propia y que se mueve de manera imprevista y muy ruidosa, obligando a los actores a luchar por su espacio y por la posibilidad de realizar sus papeles. "Los actores están humillados, echados 'fuera'. Actúan como 'a pesar de': de forma ile gal e ilícita", subraya Kantor (2005a: 251). El sentido de las palabras pronunciadas se reduce a los valores fonéticos, repetición o balbuceo, grito o intento de decirlo todo muy rápidamente, antes de que la máquina los anule, impidiendo su actuación. Las cosas se suceden dentro de la realidad del espectáculo, carecen de una lógica narrativa, y el contenido se diluye en estas proximidades del estado nulo.

\author{
Semejante aniquilación de los acontecimientos \\ su "anulación", \\ su falta de peso, \\ su sumisión al juglar, \\ permite tensarlos \\ en la acción teatral pura, \\ el elemento ${ }^{4}$ mismo del teatro. \\ Manifestación más que el método (Kantor, 1987: 88).
}

Porque según Kantor (2005a: 225) es peligroso que un acto creativo se convierta en una norma, se fosilice, despojándose de todo riesgo. Ésta debe ser la condición principal de cada artista: trabajar en un permanente estado de inseguridad, de rebelión contra lo establecido, para mantener viva la imaginación.

\title{
1.4. Teatro-happening
}

Con creces cumple esta premisa La gallina acuática, que es el único espectáculo perteneciente a la etapa teatro-happening. Esta etapa es

4. En el sentido de principio o esencia (NdA). 
quizás la más problemática o incluso utópica. Ya su nombre es un oxímoron: el teatro presupone repetición y repertorio, y el happening es un acontecimiento único e irrepetible. Como explica Kantor en una entrevista con Zbigniew Taranienko (2015: 54-55) realizada en marzo de 1973:

Hice el teatro-happening consciente de que era una utopia ideológica, es decir, el teatro podría ser un happening, primo, si no hubiera un texto literario, esa realidad artística o estética [...] y secondo, si ese teatro se hiciera una sola vez. Porque el happening es un acontecimiento que puede ocurrir solo una sola vez. El happening es una especie de estructura en la que tiene cabida bien la realidad encontrada, objet trouvé, bien la [realidad] existente, es decir, un happening se hace de lo que encontramos en un espacio. [...] En el momento en que hay cualquier elemento construido, ya deja de ser happening - éste es el principio. [...] Sabía que era una utopía. Para mi fue un intento...

El punto de partida para La gallina acuática no era tanto el texto de Witkiewicz, como la idea del viaje y los problemas, situaciones, acontecimientos y metáforas con ella relacionadas. Este concepto surgió del descubrimiento de la figura de vagabundo, un indigente que llevaba todas sus pertenencias en bolsos y bultos. Las acciones y los objetos presentados en el escenario, privados de su utilidad cotidiana, gratuitos, están confrontados con la realidad vital. El teatro-happening, llamado por Kantor también teatro de los acontecimientos ${ }^{5}$, muestra la crisis de la forma, la desenmascara y destruye. El actor, por su parte, es simplemente "una imagen desnuda del ser humano, expuesta a la vista del público" (Kantor, 2005a: 387).

En esta etapa de investigación teatral el artista polaco se opone abiertamente al método Stanislavski (sin nombrarlo) de construcción de papel, subrayando que el actor no debe crear un personaje, ni tampoco imitarlo, sino que es sobre todo él mismo en su condición de actor, con su predisposición y su propio destino. El actor tomaba el papel, siendo consciente en todo momento de su verdadera situación. Su no-actuación estaba facilitada por la separación del contenido del texto dramático (o la acción del

5. Happening significa literalmente "lo que acontece". 
texto) de la actividad de los actores (o la acción de la escena). Kantor veía la necesidad de crear dos acciones paralelas, independientes, que juntas conformaran el espectáculo.

También en el teatro-happening la no-actuación estaba condicionada por la organización del espacio escénico, que limitaba la posibilidad de movimiento del actor. En caso de La gallina acuática el espacio fue reducido por la recreación del espacio de una cafetería real: los actores tenían que moverse entre las mesas y los espectadores. Además, el espacio estaba compartido con camareros reales que atendían las mesas y servían bebidas, preguntando al mismo tiempo si “¿Eso ya ha empezado?”. En paralelo a la realización de sus personajes, los actores entraban en el espacio escénico y pedían café o se centraban en actividades ordinarias, no relacionadas con la acción principal del espectáculo (por ejemplo, llamar por teléfono o utilizar de una máquina de coser). Esas acciones eran trasplantadas por Kantor directamente de sus happenings anteriores, que por su repetición insistente durante un tiempo prolongado eran llevadas al absurdo, rompiendo con la unidad del espectáculo.

Podemos decir que Kantor utilizaba la forma de happening como una convención que de manera muy consciente introdujo en el ámbito del espectáculo teatral. La gallina acuática tomó del arte de happening su apertura formal, su irrepetibilidad, asemanticidad, falta de una trama o narración lógica, apertura a lo casual, asociaciones sueltas y la participación del público. Todo ello bajo una atenta mirada del director presente en el escenario, entre sus actores, aunque sin participar directamente en la acción. En este espectáculo, sin embargo, la interferencia de Kantor era limitada y se podía explicar por la tradición de la participación del autor-artista en el acontecimiento que organizaba.

La acción de la escena era una variación plástica de la acción del texto, no su oposición radical. Pero debemos recordar que los contenidos más importantes del teatro de Kantor no se trasmitían a través de la palabra, sino a través de la dramaturgia visual, lo que permitía su recepción también fuera de Polonia, por un público que a menudo reaccionaba con gran entusiasmo a pesar de la barrera/incomprensión lingüística. De hecho, La gallina acuática lanzó al Teatro Cricot 2 a la arena internacional, y fue presentado en Italia, Francia y en Escocia, donde en el Festival de Edimburgo logró un sonado éxito en la edición del año 1972. 


\title{
1.5. Teatro imposible
}

En 1973, el siguiente montaje de la compañía ganó el Premio Scotsman en el mismo Festival. Dandis y antiguallas fue el último espectáculo en el que Kantor utilizó un texto dramático previo -de nuevo de Stanisław Ignacy Witkiewicz-, y la puesta en escena fue el resultado de las reflexiones teóricas enmarcadas en el llamado teatro imposible. En esta etapa ${ }^{6}$ se reivindicaba la inutilidad del teatro, como una acción sin objetivo delimitado. La existencia injustificada de la obra artística, sin un propósito razonable en un mundo racional, había llevado a buscarle siempre una coartada: servir, dar testimonio, conocer la realidad, ser modelo de algo o ser un objeto de consumo (Kantor, 2005a: 453-454). Y contra ello se rebeló Kantor en el Manifiesto 1970, subrayando que "¡LA FINALIDAD NO ES INHERENTE / AL ACTO DE CREACIÓN NI A LA OBRA DE ARTE!" (Kantor, 2010: 87). Se trata de tener una actitud de contestación permanente, con el fin de mantener la conciencia artística alerta.

\author{
El Arte \\ es sobre todo \\ una manifestación \\ y acción espiritual del hombre \\ su máxima función \\ mental \\ y espiritual (Kantor, 2000: 588).
}

Destaca aquí la importancia del proceso creativo en oposición al producto final de este proceso. Pero no se trata de mostrar lo que normalmente no está a la vista del espectador, sino de una nueva forma de proceder artístico. En el teatro imposible se persigue una conducta desinteresada, inútil, el proceso creativo se convierte en el único objetivo. Esta actitud, inviable en la vida, es posible en el teatro que usa lo real como material de

6. Entre las etapas del teatro-happening y del teatro imposible Tadeusz Kantor preparó dos espectáculos: en 1970 se estrenaron en París Les cordonniers de Witkiewicz, realizados con actores franceses junto con Quartier Malakoff; y en 1974, en Cracovia, se repuso Balladyna de Słowacki, aunque en esta ocasión a Kantor fue encargada la concepción de la puesta en escena, mientras que la obra fue dirigida por Mieczysław Górkiewicz. En 1987 Kantor (2005a: 489-491) escribió un comentario, desvinculando estas dos obras de su compañía Cricot 2, alegando que se habían montado en una atmósfera no-artística de teatros profesionales y que no formaban parte del desarrollo de su teatro. 
construcción. No se busca representar una realidad externa. El último fin de su manipulación es aislar cada uno de los elementos y dotarles de una autonomía que les permita funcionar de forma independiente dentro de un espectáculo.

También el actor se despoja de sus habilidades de interpretación, se libera de la necesidad de expresar nada. Las situaciones escénicas se construyen alrededor de la figura del artista cuya atención se concentra en el objeto utilizado, lo acecha, intensificando su relación con él y creando un valor propio a raíz de esa relación (Kantor, 2005a: 552).

Actores que se representan sólo a sí mismos.

No imitan,

no exponen,

no expresan nada,

tan sólo se representan a sí mismos,

a envoltorios humanos,

son exhibicionistas,

falsificadores

que exhiben sus cualidades excepcionales,

que anexionan su personalidad

y su insólito aspecto.

[...]

Cumplen una importante condición

como prototipos del

nuevo actor (Kantor, 2010: 113-114).

Al mismo tiempo se cuestiona el lugar artístico, que habitualmente incita al espectador a sumergirse en la ilusión. La actuación entre lo real y lo ficticio implica un compromiso del actor, la anexión del azar y de lo imposible, la búsqueda de un espacio entre la ilusión y la realidad.

\subsection{Teatro de la Muerte}

Hemos visto que en dos décadas desde la fundación del Cricot 2, es decir, entre los años 1955 y 1975, hubo cinco etapas de búsqueda empírica y reflexión teórica. ¿Cinco etapas son mucho o poco? ¿Y por qué tan sólo 
seis espectáculos? Permitamos que nos conteste el propio artista:

No quiero decir que ese a menudo largo período no se podría llenar con un repertorio de un número de 'obras' siguiendo la convención desarrollada por el primer espectáculo.

Quizás de esa forma evitaríamos la acusación de que el teatro Cricot 2 es un fenómeno efímero, con funcionamiento inconsistente debido a las largas pausas entre los 'estrenos'. Que yo no sea partidario de este sistema, tiene varios motivos:

- sobre todo, los conceptos del arte y del repertorio, al pertenecer al nivel de la literatura, ganarían peso, lo que destruiría el concepto del ámbito independiente del teatro; - los períodos de explotación del espectáculo perderían el importante significado de la impregnación de la imaginación, del agotamiento de los medios de expresión, y finalmente, de la búsqueda de nuevos territorios de exploración; se convertirían en un funcionamiento normal, regular de teatro.

De esa forma desaparecería la idea misma del desarrollo (Kantor, 2000: 171).

El cambio de una etapa a otra no es brusco, aunque siempre bien delimitado. Observamos un fluido proceso de evolución de ideas. No obstante, en el año 1975 se produce una ruptura decisiva con las etapas precedentes: surge el llamado Teatro de la Muerte. En el manifiesto bajo el mismo título Kantor se ocupa de la presencia del maniquí en el teatro, polemizando abiertamente con los postulados de la supermarioneta de Edward Gordon Craig. Mantiene que los maniquíes deben compartir espacio con los actores vivos, a los que a veces incluso sustituyen y con los que pueden confundirse. Para el artista tienen un objetivo muy claro: "el maniquí en mi teatro ha de convertirse en el modelo a través del cual pasa un fuerte sentimiento de la muerte y de la condición de los muertos. Un modelo para el actor vivo" (Miklaszewski, 1992: 40).

El primer espectáculo de esta etapa, estrenado el mismo año del manifiesto, se titula La clase muerta. Logra un gran éxito internacional y se pre- 
senta en todo el mundo, de Edimburgo a Nueva York, de Italia a Japón. En varias ciudades las funciones se repiten y tienen muy buena acogida por parte del público y de la crítica, llenando siempre las salas y recibiendo varios premios. A pesar de ello, en Polonia el Teatro Cricot 2 no cuenta con el apoyo institucional y no consigue financiación para su nueva producción. De ahí que tiene que emigrar: la siguiente obra teatral de Kantor, Wielopole, Wielopole, nace en Florencia (Italia), en colaboración con el Comune di Firenze y el Teatro Regionale Toscano, y allí se estrena en el año 1980.

En este montaje se abandona por completo la utilización de textos dramáticos previos ${ }^{7}$, aunque no se niega al texto como tal. Ya no se interpretan discursos, sino ideas. Y sólo en el proceso de creación, durante los ensayos, estas ideas cobran vida y se visten con palabras. Éstas, pronunciadas por los personajes, contribuyen a la construcción del espectáculo y a menudo se convierten en un elemento crucial. En la etapa del Teatro de la Muerte estamos ante la expresión máxima de la dramaturgia espectacular a base de las reflexiones teóricas.

Para Kantor lo más importante era el equilibrio o el límite entre la ilusión y la realidad, y durante la puesta en escena tanto el actor como el espectador debían tener plena conciencia de ello. "Como guardián de este frágil equilibrio estaba el propio director, siempre presente en sus espectáculos, desempeñando diversos roles, nunca claramente determinados: director de escena, actor, mero observador... Indefinido pero indispensable" (Nawrot, 2015: 216). En el último espectáculo realizado, Hoy es mi cumpleaños, estrenado en Toulouse ya de forma póstuma (1991), la voz grabada de Kantor afirmaba:

$Y$ de nuevo estoy en ,el escenario'.

Puede que esta, costumbre' nunca

pueda ser por mí explicada claramente

ni a Ustedes ni a mí mismo.

Pero en realidad no en , el escenario',

sino en el límite.

Delante de mí: el público -

Vosotros, Ustedes, es decir

7. En La clase muerta, junto con los textos originales surgidos de los ensayos, en la partitura del espectáculo se utilizaron fragmentos del drama de Stanisław Ignacy Witkiewicz titulado Tumor Mózgowicz (Tumor Cerebróvich). 


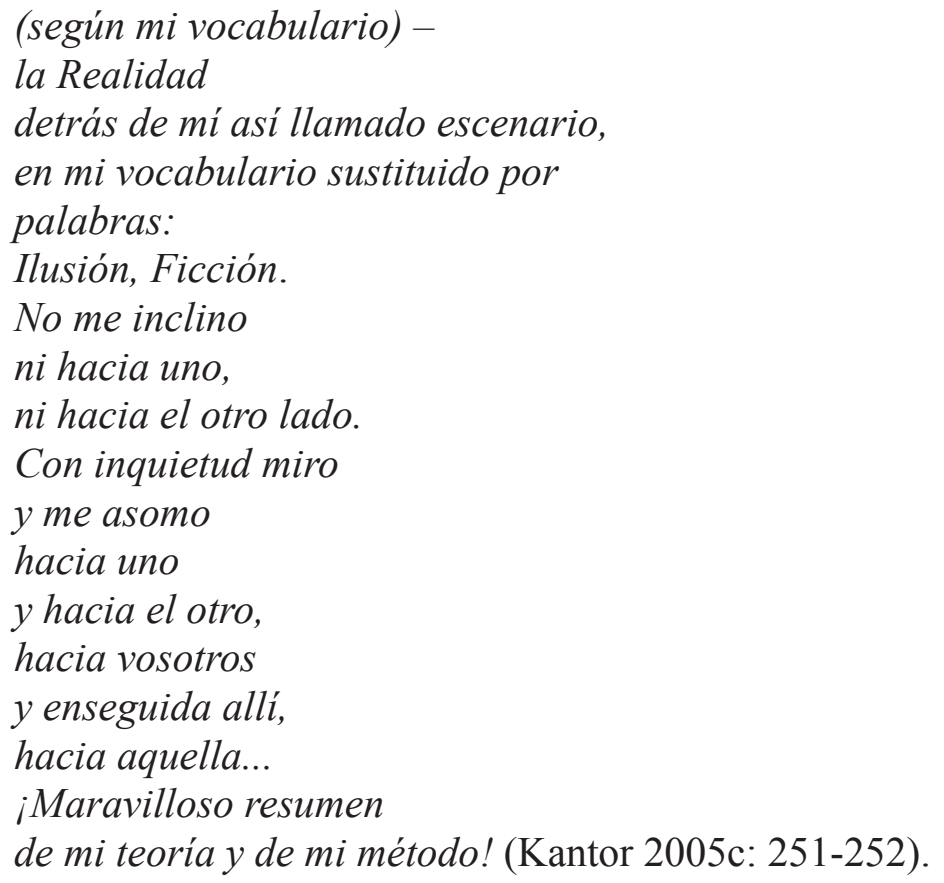

Esta última etapa se distingue de las precedentes también por el hecho de mantener los cinco espectáculos en activo. Desde el estreno de La clase muerta (1975), que dio a la compañía Cricot 2 el merecido reconocimiento mundial, se crearon cuatro obras: Wielopole, Wielopole (1980), Qué revienten los artistas (1985), Jamás volveré aquí (1988) y Hoy es mi cumpleaños (1991). Todas fueron presentadas a menudo de forma paralela en las numerosas giras a lo largo de los años ochenta del siglo XX. El Teatro de la Muerte fue el período de mayor duración, en el que se recogieron las ideas surgidas durante las etapas anteriores. En esa época, asimismo, Kantor decidió poner en orden sus reflexiones teóricas: repasó sus propios planteamientos sobre la creación artística y recopiló notas y comentarios que años más tarde se publicarían bajo la edición de Krzysztof Pleśniarowicz en la colección del Centro de Documentación del Arte de Tadeusz Kantor-Cricoteka.

\section{LECCIONES MILANESAS}

La construcción de las obras en el marco del pensamiento crítico- 
teórico original de Kantor supuso una revisión de las grandes teorías teatrales y artísticas del siglo XX. Un ejemplo clave de cómo la teoría teatral de Tadeusz Kantor se intercalaba con la dramaturgia espectacular son las Lecciones milanesas: una serie de clases magistrales pronunciadas por el artista en la Scuola Elementare d'Arte Drammatica "Piccolo Teatro" de Milán en 1986, recogidas posteriormente en forma de libro. Durante esos seminarios Kantor examinó las grandes corrientes de la vanguardia histórica (dadaísmo, abstracción, constructivismo o surrealismo) tanto en el ámbito de la pintura como en el del teatro, ofreciendo a los alumnos la interpretación de estos movimientos, así como ejemplos de su propia experiencia artística. Insistió en su sentido histórico y su todavía vigente importancia para el arte contemporáneo.

Al final de cada clase, tras un ejercicio de análisis teórico profundizado, tenía lugar un estudio práctico: los asistentes preparaban una acción escénica (por ejemplo La inmovilidad del objeto o El hombre y su sombra), que el artista polaco comentaba con todos los presentes. Es interesante notar que en una entrevista Kantor comparara el trabajo realizado en Milán con el trabajo en un taller de pintura, donde él como maestro proponía un tema, daba y explicaba un modelo, dejando un amplio espacio para que los discípulos llegaran por sí solos al resultado.

Este seminario teórico-práctico fue al mismo tiempo un taller de teatro que culminó con la puesta en escena de un espectáculo-diploma de los asistentes titulado Un matrimonio, con un significativo subtítulo que recogía la teoría estudiada durante cuatro semanas: alla maniera costruttivista e surrealista. Según las palabras de Renato Palazzi (Kantor, 1991: 7-8), la idea original de trabajar con el tema de la boda surgió de los estudiantes, pero con el transcurso del tiempo se fue impregnando del estilo kantoriano. La ceremonia del matrimonio poco a poco se iba convirtiendo en la liturgia funeral, aparecían personajes procedentes de la memoria, el escenario se llenaba de objetos pobres y desgastados. Este proceso, sin embargo, no fue impuesto por Kantor: más bien los alumnos se iban contagiando de sus ideas, asimilando su pensamiento e imitando su método de trabajar. "Poco a poco los jóvenes pasaban de ser escolares a ser seguidores, ayudantes", afirma Giovanni Raboni en la introducción a la recopilación impresa de las Lecciones milanesas (Kantor, 1991: 12). No obstante, en ningún momento el maestro intentó influir en sus elecciones. El espectáculo resultante debería mantenerse lo más cerca posible de las ideas originales y la esponta- 
neidad de los estudiantes, pero sólidamente cimentado en el conocimiento teórico.

\section{LOS ORÍGENES}

Hemos visto el modo de trabajar de Tadeusz Kantor como director del Teatro Cricot 2, pero debemos tener presente que su fascinación por las posibilidades que ofrecía el teatro había empezado mucho antes. Su primera puesta en escena, claramente inspirada en el movimiento Bauhaus, fue una función única de La muerte de Tintagiles de Maeterlinck que data de $1938^{8}$, de la que desgraciadamente no se conservan fotografías ni otros documentos originales. El espíritu de aquel montaje intentó recuperar Kantor en el cricotage 9 , titulado Macchina dell'amore e della morte, presentando en 1987 en la inauguración del Festival Documenta de Kassel (Alemania), así como en sus comentarios y dibujos realizados a partir de los años setenta.

Los más claros precedentes de la dramaturgia espectacular kantoriana se remontan, sin embargo, a la Segunda Guerra Mundial cuando su dedicación al teatro empezó a cobrar importancia. En el seno del clandestino teatro experimental, llamado también Teatro Clandestino Independiente, se realizaron dos estrenos: de Balladyna de Juliusz Słowacki (1943) y de El retorno de Ulises de Stanisław Wyspiański (1944). Ambas obras están muy arraigadas en la cultura polaca - en el romanticismo y en el modernismo - y en los tiempos de la ocupación nazi tuvieron como objetivo oponerse a la dura realidad bélica. "A causa de la escasez de materiales y la pobreza generalizada, propia de los tiempos de guerra [se utilizaron] objetos cotidianos provenientes de la realidad vital del momento [...] sacados de la basura, precursores de los elementos de la realidad del mas ínfimo rango que Kantor usará más adelante" (Nawrot, 2015: 213). Pero no fue

8. Como señala Krzysztof Pleśniarowicz: "La muerte de Tintagiles de Maeterlick es la primera obra teatral de Kantor representada en el Efímero Teatro de Marionetas, en la sede de Bratniak (una organización de ayuda estudiantil - NdT) de la Academia de Bellas Artes, en 1938 - o, como intentó averiguar Józef Chrobak, en la primera mitad de 1937-. Fue testimonio de la doble fascinación artística de Kantor: de las ideas de la vanguardia y del simbolismo (esta dualidad marcó también las obras de madurez del artista)" (Kantor, 2005a: $575)$.

9. Cricotage es un espectáculo corto cuyo nombre proviene del nombre de la compañía: Cricot 2. Por primera vez Kantor lo utilizó en 1965 como título de un happening y posteriormente lo utilizaba de forma genérica para designar formas teatrales breves, un tipo de acción derivada de la experiencia del Teatro Cricot 2 y su método de trabajar (por Halczak, 2000). 
el único rasgo retomado en los espectáculos de Cricot 2. Es significativo que ambas puestas en escena de esa época iban precedidas de un amplio trabajo de preparación teórica: reuniones y conversaciones de los artistas que participaron en aquellos proyectos. Como dice el propio Kantor:

El resultado final fue fruto de varias deliberaciones teoréticas, discusiones, reflexiones puestas por escrito. Cito algunas de ellas:

Teatro no es un aparato para la reproducción de la literatura.

Teatro es un arte autonómico.

Todos los elementos de teatro deben adquirir una autonomía completa, es decir, un grado de expresión tal que se conviertan en un valor independiente, para sí mismos.

Elementos de teatro: actor, es decir, un organismo vivo en movimiento físico, emocional, psicológico - forma - color - luz - sonido - movimiento - elemento de significado de tipo filosófico, político, psicológico, religioso - todos estos elementos en el momento que salgan de las relaciones de su lógica vital y existencia naturalista, se libran, adquiriendo gran energía y expresividad - se convierten en formas.

El texto no es una forma, sino algo que une todos los elementos de teatro.

La dualidad: escena-público lleva a la caída y crisis del teatro.

Muy importante: crear la impresión de que el público está en el escenario (y no al revés, o mezclados).

Crear tales situaciones y circunstancias que el desarrollo de los hechos en la escena pareciera imprevisto, como si se creara en este mismo momento. Crear tales circunstancias que la situación siguiente fuera una sorpresa o un choque. [...]

No se debe partir del texto, se debe llegar a él.

La creación de una realidad escénica autonómica (no en contradicción con el texto) requiere una gran concentración e imaginación. Porque esta es la creación auténtica (Kantor, 2000: 59-61). 
Como vemos, ya en los años cuarenta, a principios de su camino teatral, Kantor pensaba en la teoría teatral a partir de la cual construía después sus espectáculos. Su desarrollo estético fue un proceso complejo, y sólo conociendo la perspectiva teórica de su trabajo podemos entender plenamente sus puestas en escena. Lo que destaca es la gran coherencia de su crecimiento artístico: a pesar de los cambios realizados de una etapa a otra, es posible dibujar una línea de evolución lógica. La obra y la teoría teatral kantorianas nos llevan por el camino que habían trazado también otros revolucionarios del teatro en la segunda mitad del siglo XX. Fue un período de hervor artístico y el teatro trataba de encontrar respuestas a la realidad social, cultural y política del momento. Aunque Tadeusz Kantor subrayara siempre su independencia con respecto a otros creadores, su teatro parece aunar los postulados de Antonin Artaud y Bertolt Brecht. Por un lado, el espectáculo debe producir en el espectador una experiencia visceral, emocionarlo profundamente, pero por otro, el hecho de romper con la ilusión del escenario debe conducirlo a una reflexión racional. Porque "se acepta una responsabilidad completa al entrar en un teatro" (Kantor, 2005a: 58).

\section{REFERENCIAS BIBLIOGRÁFICAS}

HALCZAK, A. (2000). “Ostatnie cricotages Tadeusza Kantora”. Didaskalia 40, 40-46.

KANTOR, T. (1987). El Teatro de la Muerte. Selección y presentación de Denis Bablet. Prólogo a la edición en español de Kive Staiff. Traducción de Graciela Isnardi. Buenos Aires: Ediciones de la Flor. (1991). Lekcje mediolańskie. Cracovia: Cricoteka. (2000). Metamorfozy. Teksty o latach 1938-1974. Cracovia: Księgarnia Akademicka Wydawnictwo Naukowe.

(2005a). Pisma. Tom I. Metamorfozy. Teksty o latach 1938-1974. Krzysztof Pleśniarowicz (ed.). Wrocław-Cracovia: Ossolineum-Cricoteka.

(2005b). Pisma. Tom II. Teatr Śmierci. Teksty z lat 1975-1984. Krzysztof Pleśniarowicz (ed.). Wrocław-Cracovia: Ossolineum-Cricoteka. 
(2005c). Pisma. Tom III. Dalej już nic... Teksty z lat 1985-1990. Krzysztof Pleśniarowicz (ed.). Wrocław-Cracovia: OssolineumCricoteka.

(2010). El teatro de la muerte y otros ensayos (1944-1986). Selección y traducción de Katarzyna Olszewska Sonnenberg. Barcelona: Alba.

KITOWSKA-ŁYSIAK, M. (2002). Tadeusz Kantor. En http://culture.pl/ pl/tworca/tadeusz-kantor [15/04/2017].

KŁOSSOWICZ, J. (1991). Tadeusz Kantor. Teatr. Varsovia: Państwowy Instytut Wydawniczy.

MIKLASZEWSKI, K. (1992). Spotkania z Tadeuszem Kantorem. Cracovia: TKECh.

NAWROT, J. (2015). "Tadeusz Kantor en el centenario de su nacimiento". Impossibilia. Revista Internacional de estudios literarios 9, 210-218. http://ojs.impossibilia.org/index.php/impossibilia/article/view/12 [20/05/2017].

TARANIENKO, Z. (2015). Tadeusz Kantor przed "Umarla klasa". Cracovia: Cricoteka.

Recibido el 30 de mayo de 2017.

Aceptado el 26 de junio de 2017. 